\title{
Co- Excipient: Future of Formulation Industry
}

\author{
Hemant H Gangurde* \\ Department of Pharmaceutics, SSGM College of Pharmacy, Maharashtra, India
}

Submission: November 15, 2019; Published: December 06, 2019

*Corresponding author: Hemant H Gangurde, Department of Pharmaceutics, SSGM College of Pharmacy, Buldana-443001, Maharashtra, India

\begin{abstract}
This article will give complete overview on recent development in co-process excipient technology and approaches involved in its development. The co-processed excipients help to overcome deficiencies occurring with use of single general grade excipients. Formulation scientist recognized that the single component excipient cannot always provide the essential performance in manufacturing or formulation to certain active pharmaceutical ingredient (API). Hence attention on the production of multifunctional excipient with improve performance was seen to meet the need of formulation. In order to justify rise in new drug development and also high industrial output demand new combinations of existing excipient were tested for improving excipient functionality. Now days the particle engineering of individual excipient and their combinations by using co-processing technique has provided an attribute tool for developing high functionality excipients to modern drug delivery system. The co-processing is a process with interaction of two or more excipients at sub particle level which turn to provide a synergy of functionality improvement as well as masking the undesirable properties of individual excipients. It is synergistic outcome of the combination of excipients as material property into consideration. The specific excipients are best suited for particular dosage form as a selection criterion for excipients and various excipient interaction. The excipient as like of API need to be stabilized and to be standardized along with safety evaluation parameters. These co-excipients have high functionalities as compared to the individual excipients like better flow property, reduced lubricant sensitivity and compressibility.
\end{abstract}

Keywords: Excipients; Co-Processing; Particle Engineering; Novel Drug Delivery System

\section{Introduction}

In recent year scientists have found that a single excipient cannot always provide the requisite performance to allow the certain API to be manufactured or formulated. The co-processed excipients are combination of two or more compendial or noncompendial excipients which are designed to physically modify their properties in manner that are not achievable by simple physical mixing and without a significant chemical change. Development of the co-processed excipients starts with selection of excipients to be combined, preparation method, their targeted proportion to get optimized product with desired physicochemical parameters and minimizing avoidance with batch to batch variations. Excipient of a reasonable price has to be combined with optimal amount of functional material in order to obtain the integrated product, with a superior functionality than simple mixture of components. The co-processing is interesting because products are physically modified in special way without altering chemical structure. The fixed and homogenous distribution of components is achieved by embedding then within mini granules. Segregation is diminished by the adhesion of actives on the porous particles making process validation and in process reliable and easy control. Co-processed excipient enhances performance of established excipient that possess performance and improvements: in flow, increased surface area, compaction etc [1-3].

\section{Types of Excipients [2,4-6]}

Generally, types of excipients are classified into four types enlisted below:
i. Single chemical entity
ii. Physical mixture or blends of excipients
iii. New chemical entities
iv. Co-processed excipients
i. Single chemical entity

The single entity excipient is nothing, but the primary component used as excipient. It may contain other components like:

a. Concomitant component: is a balance between excipient composition and its functionality. These components should be considered as part of composition profile and hence not be construed as being a undesirable, nor confused with presence of added substance [2]. 
b. Processing Aids: are chemical substances which are used for specific processing need and benefit in excipient manufacturing process, like to improve chemical and physical process ability, to enhance a chemical synthesis reaction, to provide stabilization during the manufacturing process etc. The processing aids can be removed during the excipient manufacturing process or, depending on process clearance capability; it may remain as low level residual in final excipient. [4,5].

c. Additives: It is defined as any substance not normally consumed as a food by itself and one which is intentionally added to food, or for technical purpose in manufacture, processing, preparation or storage of such food to improve their physico-chemical properties. Normally additives are added by simple mixing process and they are incorporated in amount required to produce intended effect. Additives added not be of official grade, it should be of appropriate quality with safety been evaluated for their proposed use. Hence, the additive does not detrimental impact on excipient function and the final drug product safety/efficacy [5].

ii. Physical mixture or blends of excipients

It is a simple physical mixture or blends of two or more excipients to maintain shear processes where, individual components are mixed together without significant change. For solid mixture the individual excipients remain physically separate at particulate level. Excipient blends can be either solid or liquid after simple mixing typically for short duration $[3,4]$.

\section{iii. Novel excipients or new chemical entities}

An excipient used for first time in formulation or by a new route of administration is classified as novel or new according to the ICH Guideline. On the other hand, this guideline defines known excipients that are commonly used and well-established usually included in pharmacopoeias and used in registered drug products. When an excipient has not previously been used in a pharmaceutical formulation then there are a number of conditions set out by the US and European regulatory authorities to allow for its use. They are not fully qualified by existing safety data with respect to currently proposed level of exposure, route of administration or duration of exposure [4,5].

iv. Co processed excipients

It is a combination of two or more compendial or noncompendial excipients that are designed to physically modify properties in such manner not achievable by simple physical mixing without significant chemical change. Various methods are available for co-processing like milling, granulation, melt extrusion, spray drying etc. The choice for the specific method/ technique will depend on the material used and desired physical properties to be achieved. Likewise, ratios of the components may vary depending on target performance to attain $[2,5]$.

\section{History}

The key objective for co-processing was to achieve a product with additional value associated to the ratio of its functionality and cost. The aspect that occurs during the co-processing method is not understood absolutely but appears to achieve product components in intimate association with each other as single entity. This association cannot be achieved by simple dry blending but requires appropriate co-processing technique.

Primarily, co-processing concept was implemented in food industry to improve stability, dispersibility, gelling properties of food additives. Few co-processed combinations used were Micro crystalline cellulose (MCC) and galactomanan with glucomannan, MCC with Carboxy methyl cellulose (CMC) and sodium alginate complex.

In pharmaceutical industry, the co-processing concept was established in early 1990 with the introduction of co-processed combinations like MCC and calcium carbonate. Cellactose is a co-processed combination of cellulose and lactose, ProSolv is a combination of MCC and colloidal silicon dioxide $[7,8]$.

\section{Excipients Selection Criteria in Co-Processing}

The combination of excipient selected for co-processing should compatible and non-reactive to each other. For example, two hexitol group excipient Mannitol: Sorbitol are co-processed to achieve good compressibility as tablet excipient where first is poorly compressible and less hygroscopic and later is good compressible but highly hygroscopic to create balance between plasticity and brittleness. A few other examples of co-processed excipients studied are combination of Lactose: PVP K30: Starch as a ready to use excipient for tablet with diluents, binder and disintegrant property, MCC: Sodium starch glycolate for direct compression immediate release formulations, Dibasic Calcium Phosphate dihydrate co-processed with Pre gelatinised starch for direct compression with binder and diluents property [9-12].

\section{Regulatory Aspects in Co-Processed Excipient}

Excipients combinations through co-processing do not produce any chemical modification in the incorporated excipients. Individual properties of excipient are retaining in the combination, the only novelty is the improved functionality with same physical form. Hence, the co-processed combination does not require any toxicological study and can be considered safe if the parent excipients are declared safe by the regulatory agencies GRAS. Very few co-excipients are described in official monograph like Dispersible Cellulose in B.P., Compressible Sugar in U.S.P/NF. Their non-compendial status is the major hurdle in the success of coprocessed excipient in the market. This obstacle will be overcome in the coming future as with New Excipient Safety Evaluation Procedure (NESEP), and excipients now could be reviewed outside the FDA drug approval process. Affirmative opinion from experts 
of IPEC team will limit the risk of FDA dismissal of drug based on excipient and could encourage innovation in the pharmaceutical industry $[13,14]$.

\section{Current \& Future Status of Co-process excipients}

At present co-processed excipients have less applicability in the pharmaceutical industry but surely these will be utilized with enhanced functional properties at low concentration in future. Very few new chemical entities are being introduced in market due to stringent rules and regulations by considering safety, efficacy, and cost. Also, very few improvements in existing excipients will help in increased use of co-processed excipients in coming future. Uprising technologies and many more modification are implementing daily in Pharmaceutical industry to achieve high production rate. A growing popularity of high functionality excipients counterpart tablet machine increasing speed capabilities, to modulate the permeability, solubility, or stability of drug, increasing performance expectations related to disintegration, dissolution, bioavailability etc. makes a fantastic opportunity for the development of novel drug delivery system.
Forthcoming novel excipient combinations and new co-processing techniques without any doubt going to attract both in research and pharmaceutical industry $[15,16]$.

\section{Fundamental solid-state properties of excipient}

The solid-state properties are characterized by three levels as molecular, particle and bulk. These levels are closely linked with each other, reflecting change in one level with another level shown in (Figure 1). The first molecular level is crystal lattice and include phenomenon such as polymorphism, pseudo polymorphism and amorphous state. The second level consist of individual particle size, shape, porosity, and surface area. The third is bulk level comprises of a group of particles and their physical properties. The individual levels depend over each other which provides framework for the development of novel combination of existing and new grade of excipients. The essential solid-state properties of particles like morphology, size, shape, porosity, density, surface area influence excipient functions such as flowability, dilution, lubrication and disintegrating potential, compressibility and Compatability.

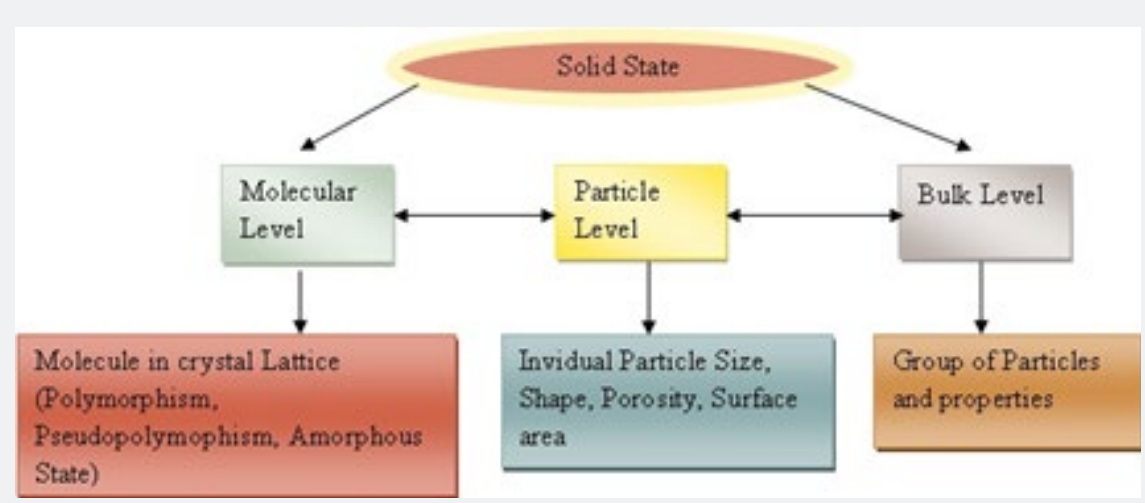

Figure 1: Levels of Solid State.

The primary characteristic associated with excipient is that no chemical change occur during co-processing and also the reflected changes showed in the physical properties have to prove that coexcipient do not show any chemical change. There should not be covalent bond formation when these individual ingredients are combined to form co-excipient. Also, stereochemical environment, reorientation, bond breaking and the intermolecular forces responsible for new shapes confirms the formation of a new composition. Analytical techniques for characterization used like particle size distribution, specific surface area, SEM images and $\mathrm{X}$-ray diffractogram (XRD) etc. However, the techniques NMR, HPLC, FTIR, DSC, are used in order to aid control their structural properties [17-19].

\section{Methods of Coprocessing [20-25]}

i. Spray Drying. ii. Solvent Evaporation.

iii. Crystallization.

iv. Melt Extrusion.

v. Granulation/Agglomeration

i. $\quad$ Spray Drying

This technique is applicable for transformation of feed from fluid state into dried particulate form by spraying the feed into the hot drying chamber. It involves continuous drying operation processing. The feed may be in the form of solution or suspension. The dried product can be obtain in powders, granules or agglomerates depending upon it's physical and chemical properties, dryer design and final powder properties desired. The spray drying combination of ingredient under solid or dry form during drying, by atomizing active compound in suspension or solution form (Figure 2). 


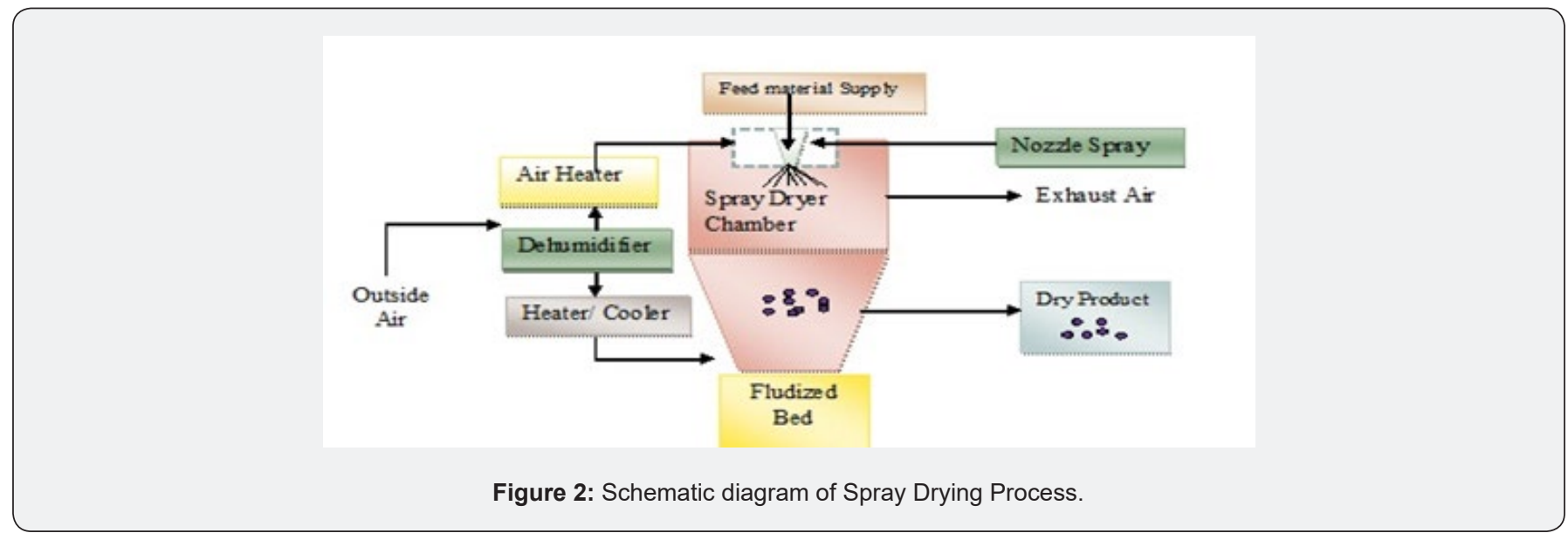

\section{ii. Solvent Evaporation}

It involves use of liquid as a vehicle to dissolve excipient in organic solvent in which it is immiscible. A core excipient material are also microencapsulated in dissolved or dispersed liquid phase to obtain appropriate size microparticles. The mixture is then heated if necessary, to evaporate the solvent. Once all the solvent gets evaporated, the mixture temperature is reduced to ambient temperature (if required) with continuous agitation. Also, the particles can be used in isolated form as powders or coated sub states. The obtained material can be either water soluble or insoluble depending on material property. After complete drying of obtained mixture is in the form of new single entity co-excipient $[26,27]$.

\section{iii. Crystallization}

Crystallization is a solid crystals formation process of precipitating naturally or artificially from the solution and rarely deposited directly from a gas. It is a chemical solid-liquid separation technique, in which mass transfer of solute from the liquid to crystalline solid is obtained and it must be supersaturated. It means that solution has to contain more solute dissolved, unless equilibrium i.e. Supersaturation is achieved. It can be achieved by various methods such as, solution cooling, addition of second solvent to reduce solubility of the solute or by chemical reaction. Change in $\mathrm{pH}$ is one of the most common method used in industry for crystallization.

\section{iv. Hot Melt Extrusion}

The technique involves mixing of co-processed excipients with meltable binder on a water bath, and then cooling agglomerates to solidify the mass which is subsequently pass through sieve for size reduction. It is a solvent free technique and requires a less processing time. The concentration of selected excipient ratio is a critical variables in the process. The process is a formation of small pellets, beads from the molten mass which is an extruded through extruder. Schematic presentation shown below (Figure $3)$.

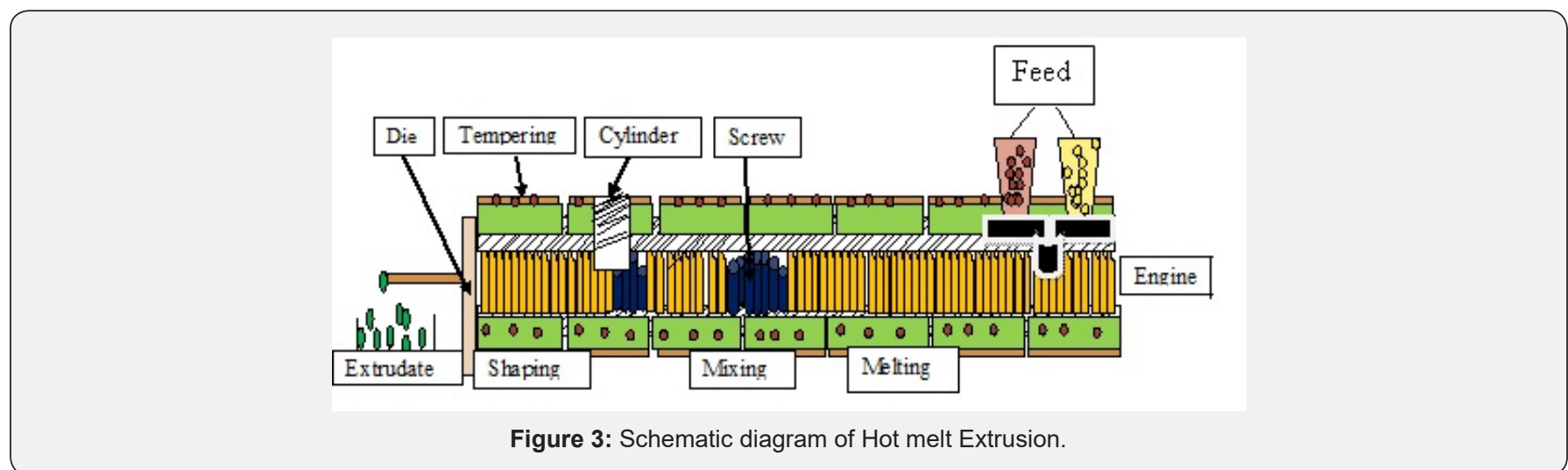

\section{v. Granulation /Agglomeration}

The granulation is a process of forming or crystallizing into grains. The granules typically have size range between 0.2 to $4.0 \mathrm{~mm}$ depending on their use. The Agglomeration is synonymous to granulation process involves particle size enlargement technique to alter product properties. The Agglomeration process is widely used to enhance physical properties like flowability, bulk density, wettability, and product appearance. In pharma industry two types of granulation technologies are employed, mainly dry and wet granulation. Wet granulation is a more preferred method for co-processing (Table 1). 
Table 1: Example of Coproceed Excipients.

\begin{tabular}{|c|c|c|c|c|}
\hline $\begin{array}{l}\text { Sr. } \\
\text { No. }\end{array}$ & Trade Name & Composition & Advantage & Manufacturer \\
\hline 1 & Ludipress 2,4,18 & $\begin{array}{c}\text { Lactose,3.2\%Kallidone Kallidone } \\
\mathrm{Cl}\end{array}$ & $\begin{array}{l}\text { Low degree of hygroscopicity ,Good Flow- } \\
\text { ability, }\end{array}$ & Basfag, Germany \\
\hline 2 & $\begin{array}{l}\text { Cellactose/Microcelac } \\
1002,4\end{array}$ & Lactose, $25 \%$, Cellulose & $\begin{array}{l}\text { Improved flow property, Excellent binding } \\
\text { \& high dilution potential }\end{array}$ & $\begin{array}{l}\text { Megglegmbh \&co.kg,ger- } \\
\text { many. }\end{array}$ \\
\hline 3 & Pharmactose DCL40 4,14 & $\begin{array}{l}95 \% \beta \text {-Lactose \& } 5 \% \text { anhydrous } \\
\text { lacitol }\end{array}$ & $\begin{array}{l}\text { Very Low water uptake at high humidity, } \\
\text { Good flow ability, high dilution, \& better } \\
\text { binding property }\end{array}$ & DMV \\
\hline 4 & $\begin{array}{l}\text { Prosolv/Silicifid micro- } \\
\text { crystalline cellulose } 26\end{array}$ & $\begin{array}{l}98 \% \text { microcrystalline cellulose \& } \\
2 \% \text { colloidal silicon dioxide }\end{array}$ & Better tablet performance at lower cost & JRS \\
\hline 5 & Starlac 27 & Lactose $85 \%$, maize starch15\% & Good Flowability & Meggle \\
\hline 6 & Ludiflash 4,18 & 90\%mannitol,5\%CLSF, \%SR30D & $\begin{array}{l}\text { Rapidly disintegrating, mechanically stable } \\
\text { tablets. }\end{array}$ & BASF \\
\hline 7 & Avicel CE 2,4,18 & $\begin{array}{l}\text { Solution of MCC } 85 \% \text {, Guar gum } \\
\qquad 15 \%\end{array}$ & $\begin{array}{l}\text { Provide smooth, creamie mouth feel, less } \\
\text { tooth packing, without scarifying flow or } \\
\text { compaction }\end{array}$ & FMC \\
\hline 8 & Dipac 2,4 & $\begin{array}{l}\text { 97\% small sucrose crystals, } 3 \% \\
\text { highly modified starch }\end{array}$ & $\begin{array}{l}\text { High flowability, low hygroscopicity, sweet, } \\
\text { nonreactivity with other components }\end{array}$ & Domino \\
\hline
\end{tabular}

\section{References}

1. Patil A, Subrata, Srinivasan G( 2013) A Review on Co-processed Excipients : A Novel Approach In Formulation Development. Int J of Pharm Innov 3(5): 25-41.

2. Allamneni N and Suresh JN (2014) Co-processed Excipients As a New Generation Excipients With Multifunctional Activities : An Overview. Ind J of Pharm Sci Res 4(1): 22-25.

3. Chaudhari PD, Phatak AA, Desai U (2012) A Review: Co-processed Excipients - An Alternative to Novel Chemical Entities. Int J of Pharm and Chem Sci 1(4): 1824-1842.

4. Mamatha B , Srilatha D, Sivanarayani CH , Desu P, Venkateswara Rao P (2017) Co-Processed Excipients : An Overview. World J Pharm Res 6(15): 224-237.

5. Kathpalia H, Jogi K (2014) Coprocessed Excipients - A Review. World J Pharm Res 3(3): 3863-3885

6. Bhor NJ, Bhusare SE, Kare PT (2014) Multifunctional Excipients: The Smart Excipients, Int J of Pur Appl Bio 2(5): 144-148.

7. Garg N, Dureja H, Kaushik D (2013) Co-Processed Excipients : A Patent Review. Recent Patents on Drug Delivery And Formulation, Bentham Science Publishers 7(1): 73-83.

8. Gohel MC (2005) A review of co-processed directly compressible excipients. J Pharm Pharmaceuti Sci 8(1): 76-93.

9. Deorkar N, FarinaJ,Miinea L, RandiveS(2011) Directly compressiblehigh functionality granular microcrystalline cellulose based excipient, manufacturing process and use thereof. US20110092598.

10. Mcginley EJ, Tuason DC (1995) Microcrystalline cellulose and glucomannan aggregates. W09526643.

11. Modliszewski JJ, Ballard AD (1995) Co-processed galactomananglucomannan. W09517831.

12. Reimerds D (1993) The near future of tablet excipients. Manuf Chem 64(7):14-15.

13. Carlin BA (2008) How Co processing takes place in excipient manufacturing. Paper presented at: IPEC Americas Regulatory Affairs Meeting.
14. Desai U, Chavan R, Mhatre P, Chinchole R (2012) A Review : Coprocessed Excipients. Int J of Pharm Sci Rev and Res 12(2): 93-105.

15. Uppuluri P, Chakraborty T, Devi VK, Raichur V (2014) Preparation of Novel Co-Processed Excipient -Study of Flow Properties and Compatability. Indo Ame J of Pharm Res 4(10): 5074-5081.

16. Kanojia N, Kaur L, Nagpal M, Rajni B (2013) Modified Excipients In Novel Drug Delivery : Need of the day. J Pharm Tec Res And Manage 1: 81-107.

17. Ambore SM, Tekale J, Gattani SG (2014) Investigation of Novel Multifunctional Co-Processed Excipient For Direct Compression. World App Sci Journal 31(5): 801-810.

18. Patil PR, Andhale VA, Dhas AV (2016) Directly Compressible Coprocessed Pharmaceutical Excipients. Int J of Pharm and Tech 8(1): 3648-3670.

19. Patil A, Kadam VJ, Jadhav KR (2010) Co-Processed Pharmaceutical Excipients - A Brief Review. Research J Pharm, and Tech 3(1): 50-57.

20. Saha S, Aliasgar FS (2009) Multifunctional Co-processed Excipient For Improved Tabletting Performance. Expert Opinion on Drug Delivery 6(2):197-208.

21. Apeji YE, Aluga D, Olayemi OJ, Oparaeche C, Anyebe SN, et al. (2017) Comparative Analysis of Co-Processed Starchecs Prepared By Three Different Methods. Brit J of Pharm 2(1): 55-69.

22. Gattani M, Singh V, Shukla MA, Ahire K, Singh M (2013) Development of Directly Compressible Co-Processed Excipients For Orally Disintegrating Tablets Using Rotary Evaporation Method Int J Pharm Pharm Sci 5(3): 390-395.

23. Patel H , Gohel M (2016) A Review On Development of Multifunctional Co-Processed Excipient. Journal of Critical Reviews 3(2): 48-54.

24. Liew KB, Anand G, Mandal U (2019) A review on co-processed excipients: Current and future trend of excipient technology. Int J Pharm Pharm Sci 11(1): 1-9.

25. Patel MA, Pingale PL (2014) High functionality coprocessed excipients: A review. World J Pharm Pharm Sci 3(3): 795-806

26. Aljaberi A, Ardakani A, Khdair A, Abdel Rahim SA, Meqdadi E (2013) Tabletting Functionality Evaluation of Prosolv Easytab in Comparison 
to Physical Mixture of It's Individual Components. J Drug Del SciTech 23(5): 499-504

27. Olowasulu AK, Oyi AR, Isah AB, Ibrahim MA (2014) Dilution Potential and Filler- Binder Functionality of Starch Based Co-Processed

This work is licensed under Creative Commons Attribution 4.0 License
Excipients (Starlac) in The Formulation of Metronidazole Tablets. Nig J of Pharm Sc.

\section{Your next submission with Juniper Publishers} will reach you the below assets

- Quality Editorial service

- Swift Peer Review

- Reprints availability

- E-prints Service

- Manuscript Podcast for convenient understanding

- Global attainment for your research

- Manuscript accessibility in different formats

( Pdf, E-pub, Full Text, Audio)

- Unceasing customer service

Track the below URL for one-step submission https://juniperpublishers.com/online-submission.php 